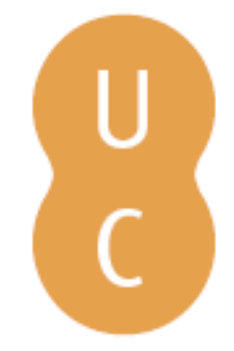

\title{
nommalina
}

\section{El mito de Transilvania en la España de Carlos II: imagen, identidad y conflicto en las noticias impresas durante la Guerra Austroturca}

\author{
Autor(es): $\quad$ Gómez Sánchez-Ferrer, Guillermo \\ Publicado por: Imprensa da Universidade de Coimbra \\ URL \\ persistente: URI:http://hdl.handle.net/10316.2/44014 \\ DOI: $\quad$ DOI:https://doi.org/10.14195/978-989-26-1550-9_12 \\ Accessed : $\quad$ 26-Apr-2023 14:48:00
}

A navegação consulta e descarregamento dos títulos inseridos nas Bibliotecas Digitais UC Digitalis, UC Pombalina e UC Impactum, pressupõem a aceitação plena e sem reservas dos Termos e Condições de Uso destas Bibliotecas Digitais, disponíveis em https://digitalis.uc.pt/pt-pt/termos.

Conforme exposto nos referidos Termos e Condições de Uso, o descarregamento de títulos de acesso restrito requer uma licença válida de autorização devendo o utilizador aceder ao(s) documento(s) a partir de um endereço de IP da instituição detentora da supramencionada licença.

Ao utilizador é apenas permitido o descarregamento para uso pessoal, pelo que o emprego do(s) título(s) descarregado(s) para outro fim, designadamente comercial, carece de autorização do respetivo autor ou editor da obra.

Na medida em que todas as obras da UC Digitalis se encontram protegidas pelo Código do Direito de Autor e Direitos Conexos e demais legislação aplicável, toda a cópia, parcial ou total, deste documento, nos casos em que é legalmente admitida, deverá conter ou fazer-se acompanhar por este aviso.

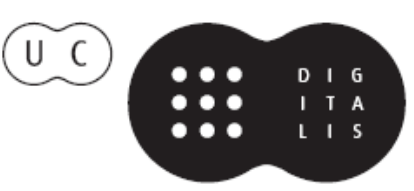




\section{Desplazamientos de la tradición clásica en las culturas hispánicas}

Paola Bellomi, Claudio Castro Filho, Elisa Sartor (eds.)

IMPRENSA DA UNIVERSIDADE DE COIMBRA 


\title{
El mito de Transilvania en la España de Carlos II: IMAGEN, IDENTIDAD Y CONFLICTO EN LAS NOTICIAS IMPRESAS DURANTE LA GUERRA AUSTRO-TURCA ${ }^{1}$ \\ (The myth of Transylvania during the reign of Charles II of Spain: image, identity and conflict in the News printed during the Great Turkish War)
}

\author{
Guillermo Gómez Sánchez-Ferrer \\ Universitat Autònoma de Barcelona (Orcid: 0000-0002-4319-4840)
}

\begin{abstract}
Resumen: El presente trabajo se adentra en un tema históricamente bien conocido, la guerra austro-turca sostenida entre 1683 y 1690, pero poco analizado en función del relato que se hizo de los acontecimientos bélicos para los lectores de España. Por ello, ofrecemos aquí una panorámica de esa "guerra de papeles" impresos. En ella atendemos a la imagen creada para el lector hispanohablante de las tierras de Transilvania, presentadas con un marcado carácter mítico que es reflejo del conflicto armado y cultural que tuvo lugar entre la parte oriental y la occidental de Europa. El análisis de dichos impresos, tanto en sus características formales como en su contenido, permite constatar que el relato del conflicto ayudó a crear una imagen literaria de las regiones rumanas en España. Con ello, finalmente, atenderemos a uno de los objetivos del proyecto Oltenia en los siglos $X V$-XIX, en el que se enmarca nuestro trabajo: entablar un debate internacional e interdisciplinario sobre la manera en la que el espacio rumano es percibido en España en la Edad Moderna.
\end{abstract}

Palabras clave: relaciones de sucesos, Transilvania, guerra austro-turca, ficcionalización.

АвsтRAст: This paper ventures into the Great Turkish War, which took place between 1683 and 1690, a subject historically well known, but rarely studied according to the way the military events were narrated to the Spanish readers. Therefore, in this work, I will offer the bigger picture of this "war of the printed newspapers". I will approach, as well, the image of the Transylvanian land created for a Spanish-speaker reader. It is characterised by a mythical halo that can be considered the reflection of an armed and cultural conflict that took place between Eastern and Western Europe. The physical and literary analysis of those printed documents will allow us to identify how the literary image of the Romanian regions was created for Spain. Finally, I expect to be

${ }^{1} \mathrm{El}$ presente trabajo forma parte del proyecto de investigación Oltenia en los siglos $\mathrm{XV}$ -XIX: las relaciones de los países rumanos con Europa occidental a la luz de los documentos (AR1235/21.12.2015) desarrollado en la Academia Rumana de Craiova y dirigido por la Dra. Oana Andreia Sâmbrian, cuyo propósito es explorar a fondo las relaciones rumano-españolas durante la Edad Moderna. Asimismo, para el presente trabajo ha resultado indispensable la ayuda de Rosario Martínez Navarro, desde la biblioteca de la Universidad de Sevilla, y de Jessica Cáliz Montes, desde la biblioteca de la Universidad de Barcelona. Quede constancia aquí de mi agradecimiento a todas ellas. 
able to fulfill one of the objectives of the project Oltenia in the $15^{\text {th }}-19^{\text {th }}$ Centuries, in which this paper may be included: to initiate an international and interdisciplinary debate about how the Romanian space is perceived in Spain in the Modern Age.

KeYwords: news pamphlets, Transylvania, Great Turkish War, fictionalisation.

No es ningún misterio para quienes nos dedicamos a los estudios humanísticos que el discurso determina el contenido. No hay redacción alguna de la memoria que esté libre de las parcialidades que - de manera consciente o inconsciente - implica la selección de los hechos más relevantes para hacer la crónica de una época. Los historiadores y los filólogos que trabajamos sobre los documentos de la Edad Moderna, cuando menos, hemos tomado buena nota de ello. Desde finales de los años noventa se ha empezado a prestar atención de manera decidida y organizada a la forma en que se trasmiten los productos relacionados con la imagen de los regentes y sus gobiernos en el siglo XVII. Así, en estos últimos años se ha podido vincular la labor de algunos escritores a la promoción (o denuesto) de la actividad política de los dirigentes del país en casos tan destacados como el de Lope de Vega (García Reidy 2013), Francisco de Quevedo (Gutiérrez 2005, Arredondo 2011), Calderón de la Barca (Brown y Elliott 2003, De Armas 2016) o Bances Candamo (Duarte 2007, García Castañón 2011). A fin de cuentas, la literatura (entendida en un sentido amplio) que más se consumió en el tiempo de la imprenta manual es la que daba forma a la opinión pública en torno a los temas más relevantes para el buen gobierno.

Las palabras de Peter Burke al filo del último cambio de siglo alertaban precisamente sobre los peligros de la memoria y de la influencia de los grupos de poder a la hora de construir una imagen fiable del pasado:

La cuestión es que todos tenemos acceso al pasado (y al presente) únicamente a través de las categorías y esquemas —o, como diría Durkheim, las "representaciones colectivas"- de nuestra propia cultura [...]. La historia social de la memoria intenta responder a tres grandes preguntas: ¿cuáles son las formas de transmisión de los recuerdos públicos y cómo han cambiado en el tiempo? ¿Cuáles son los usos de esos recuerdos, del pasado, y cómo han cambiado? Y, a la inversa, ¿cuáles son los usos del olvido? (2000: 68-69)²

\footnotetext{
${ }^{2}$ Mucho más recientemente advertía de lo mismo Ovidiu Cristea, director del instituto de Historia de Bucarest "Nicolae Iorga", en una entrevista hecha por Oana Sâmbrian. Su testimonio nos interesa especialmente, dado el tema de este trabajo. Allí enfatizaba el hecho de que: "As every historian knows there are no innocent testimonies and the foreign travellers are sometimes full of prejudices, chlichés, misunderstandings" (Sâmbrian 2013: 23-24). En los relatos de los viajeros por los países rumanos a los que se ha dedicado en los últimos años, la imagen del país "depended on what the traveller expected to find and on his general knowledge" (Sâmbrian 2013: 24). Así, "a Westerner would probably notice that the Wallachians and Moldavians belong to the orthodox faith; a military expert (as Filippo Pigafetta of Silvio Piccolomini)
} 
El mito de Transilvania en la España de Carlos II: imagen, identidad y conflicto en las noticias impresas durante la guerra austro-turca

También en lo tocante a la literatura y a las formas impresas del Siglo de Oro (el ámbito de estudio que aquí nos concierne) se ha explorado esa esfera de conocimiento tan escurridiza gracias a varias iniciativas en las que se unen la filología y la historia de manera complementaria. De este modo, al menos, se encuentra en la amplísima bibliografía de estudios dedicados a la representación —en textos literarios - de la autoridad y poder durante el Siglo de Oro (Sáez 2011). No solo eso, según plantea Gernet (1981) en uno de sus artículos más conocidos, la historia es susceptible de reconceptualizarse a partir de una serie de notas míticas comunes a todo tipo de situaciones. En consecuencia, la ficcionalización o la recreación de la realidad histórica se puede encontrar también en los textos de la Edad Moderna. En el caso que aquí nos interesa, y a partir del momento en que se trascienden los textos estrictamente literarios, dicha peculiaridad se advierte con fuerza en las hojas volanderas de carácter noticiero que circularon casi desde el mismo momento en que se asentó la imprenta en la Península Ibérica. Las relaciones de sucesos (sobre todo las que empezaron a aparecer en series durante el siglo XVII) consiguieron una notable difusión tanto de los hechos más relevantes para la historia de Europa como de la visión con que se narraban tales acontecimientos. No resulta descabellado comprobar, en consecuencia, que en esos casos la historia recibe una considerable pátina ideológica, a veces incluso mitológica. En el discurso escrito (e impreso) en esas hojas están operando los mismos códigos que se encuentran en las noticias de las fiestas barrocas que se imprimieron a lo largo del Siglo de Oro, sobre los que aseguraba López Poza:

En todas las sociedades se han creado códigos de lenguaje ocultos y símbolos para diferenciar el "nosotros" de "los otros". Esos códigos apelan directamente al inconsciente y actúan de manera poderosa, contribuyendo a la creación de estereotipos que afloran en el arte, en los sueños, en la literatura... en forma de imágenes mentales simplificadas acerca de un grupo de gente o una categoría que comparte algunas características. Esos estereotipos no se guían por la lógica, sino por las emociones y son de diferente naturaleza, aunque predominan las asociadas a la raza y las costumbres sociales. La mente tribal que poseen los humanos, como la ha denominado David Berreby tiende a clasificar a los demás en categorías y a juzgarlos en función de ellas. (López Poza 2009: 425)

Si tomamos por ejemplo los pliegos sueltos difundidos en el momento álgido de los conflictos que tuvieron lugar en Cataluña y Portugal a partir de 1640 (Ettinghausen 1993, Valladares 2002, Arredondo 2011, Domènech 2016), no parece quedar mucho lugar para la duda. Al leer las series de noticias que

would underline the lack of fortifications while a merchant (as Martin Gruneweg) would point to the opportunities for trade" (Sâmbrian 2013: 24). 
se imprimieron entonces podremos encontrar la construcción de una imagen anclada en algunos de los mitemas propios de los héroes clásicos, que van desde la exaltación de la "valentía catalana" ${ }^{3}$ hasta la Comparació de Cathalunya ab Troya (Barcelona, Jaume Romeu, 1641), pasando por la condición de Pau Claris como personaje elegido para liderar a su pueblo a la victoria ${ }^{4}$.

El pliego suelto, entendido como instrumento político, permitió repensar desde una configuración mítica algunas de las guerras en las que participó la potencia hispánica en el siglo XVII. A fin de cuentas, acudiendo a las palabras de López Poza una vez más, se puede decir que:

En las relaciones, advertimos que la jerarquía civil y eclesiástica en la Europa de los siglos XVI-XVIII sabía hacer buen uso de los símbolos y atributos para estereotipar tanto al noble (asociado siempre a la ortodoxia, y por ello a signos positivos) como a quienes se desviaban de las pautas sociales o religiosas ("los otros") a quienes se denostaba simbólicamente con atributos de gran eficacia y evidencia. Se pretendía hacer sentir fuertes a los "ortodoxos", los leales al sistema, ridiculizando las desviaciones y alimentando las fobias contra enemigos ideológicos. (López Poza 2009: 427-428)

Las incipientes Novas y Gazetas que se distribuyeron en los reinos peninsulares introdujeron poco a poco en los hogares castellanos la realidad del resto de Europa y, junto con ella, la imagen (positiva o negativa, real o mítica) de algunos de los rincones más remotos del mundo ${ }^{5}$. En ese contexto se deben situar también las relaciones del siglo XVII relativas a Transilvania (y, en menor medida, a Valaquia y Moldavia), viejos conocidos del lector peninsular de noticias y avisos desde que jugasen un papel decisivo en la oposición al Imperio otomano por parte de la Liga Santa a finales del XVI.

Sus hechos fueron difundidos por extenso desde las prensas de Sevilla, Granada o Valencia (Redondo 2003, Sâmbrian 2015: 41-45). Con todo, los sucesos de esa ínsula de independencia en medio de un océano otomano, que fueron los condados rumanos, no se limitaron a las heroicidades políticas de los últimos años del Quinientos. Más tarde, ya en pleno siglo XVII, se pueden rastrear algunos datos históricos relativos a las tierras transilvanas en épocas especialmente conflictivas

${ }^{3}$ Así se destaca, al menos, en el Clari de Veritats, valentia catalana, derrota de castellans alumbrats, retiro, y galliner de Madrit, gall y flor de lliri de França (Barcelona, Gabriel Nogués, 1641).

${ }^{4}$ Según Verjat (2000) los tres "mitemas del héroe" son: el anuncio "heráldico" de un destino excepcional; los trabajos y hazañas sobre los que debe triunfar; y la revelación del secreto o del tesoro que debía encontrar y para los cuales representaba una necesidad narrativa.

${ }^{5}$ Asegura Agustin Redondo sobre las relaciones de la guerra contra el Turco de finales del siglo XVI que: "Las relaciones de sucesos han desempeñado un papel activo al difundir entre lectores y oyentes una serie de informaciones, reales o inventadas, acerca de los turcos. Estas relaciones atañen tanto a los encuentros bélicos como a otras manifestaciones del tema (profecías, prodigios, milagros, costumbres, etc.) y revelan una significativa puesta en obra narrativa” (2003: 237). 
para Europa. El caso más claro es el periodo que se extendió durante la guerra de los Treinta Años (1618-1648) (Sâmbrian 2015). La imagen de Transilvania transmitida en estos años cambia radicalmente la visión anterior, pues las relaciones y los tratados empiezan a situar a los países rumanos - $\mathrm{y}$, sobre todo, al príncipe transilvano Gabriel Bethlen, "tirano de Transilvania” (Pellicer y Tovar 2006: 73) — entre los enemigos de la cristiandad y traidores a la antigua amistad que habían mantenido con España. Contrasta esta imagen con la que existía a finales del siglo XVI, cuando las tierras rumanas ostentaban un carácter mítico y heroico gracias a los prósperos sucesos del serenísimo príncipe de Transilvania contra los turcos, quien se había convertido en trasunto de Pirro, Aníbal o Escipión el Africano para el autor de la Relación de todo el cerco de Temesuar (1596). Treinta años más tarde, sin embargo, se habían convertido en la némesis del imperio cristiano.

En efecto, al llegar a 1635 se publicaba en Venecia el tratado de José de Pellicer y Tovar escrito en Defensa de España contra las calumnias de Francia, en el que se habla sin ambages de "los transilvanos, infestadores de la Hungría y la Bohemia [...] amigos, confederados y parciales de Francia, eternos y jurados enemigos de la Monarquía de España” (2006: 85). También Diego de Saavedra Fajardo es del mismo parecer, según se entrevé en sus tratados y - sobre todo- en sus cartas al rey ${ }^{6}$. Con todo, el papel de las municipalidades rumanas no fue baladí al final de esa guerra para difundir por el este europeo sus noticias. Dice Sâmbrian al respecto:

În plan politic, implicarea nemijlocită a Transilvaniei în războiul de treizeci de ani a avut un impact preponderent favorabil asupra felului în care principatul a fost perceput în plan extern, la pacea de la Westfalia, încheiată la scurt timp după moartea lui Gheorghe Rákoczi I, Transilvania participând ca stat suveran, recunoscut de celelalte țări europene. $(2015: 30)^{7}$

Si avanzamos aún más en el tiempo, comprobaremos que la campaña propagandística contra el enemigo transilvano que se llevó a cabo durante la guerra de

${ }^{6}$ Dice al respecto Saavedra Fajardo en una de sus cartas a Felipe IV: "Mayores [daños de proseguir la guerra] se verán de otro tratado que he enviado a imprimir a Bruselas, sin autor ni lugar, en el cuál están todos los Tratados de Ligas y confederaciones de Francia con holandeses y sueceses, y la que últimamente han hecho con Suecia y el príncipe de Transilvania, a daño del Imperio y de la cristiandad, poniendo algunas cartas intercetas [sic] del embajador de Francia, residente en Constantinopla, escritas al transilvano, en que le avisa de las diligencias que hacía con el Turco para que le diese licencia de entrar con sus armas en Hungría [...]” (Boadas Cabarroca 2012: 74; González Cañal 1987). Según Sâmbrian, por su parte, hay tres motivos de conflicto muy presentes en las noticias difundidas en España en esa época: católicos versus protestantes; Francia versus los países católicos; y la alianza versus la Casa de Austria (2015: 13).

7 "En lo político, la participación directa de Transilvania en la guerra de los Treinta Años tuvo un impacto favorable, sobre todo, por difundir el modo en que se percibió externamente la Paz de Westfalia, que terminó poco después de la muerte de George Rakoczi I, cuando Transilvania se convirtió en un estado soberano reconocido por otros países europeos". 
los Treinta Años por medio de los panfletos impresos en talleres como los de los sevillanos Francisco de Lyra y Simón Fajardo empezó a cambiar nuevamente con el siguiente gran enfrentamiento europeo. En 1683 se recrudece la Gran Guerra Turca, conflicto que afectará definitivamente a la configuración de Transilvania, Valaquia y Moldavia, poniendo a las municipalidades rumanas —en palabras de Hitchins (2014) - en camino hacia la Modernidad. Si bien todavía dependían en gran medida del emperador turco ${ }^{8}$, el recelo con que se miraba desde España al este de Europa, por considerar que allí se encontraba un firme defensor de la pérfida Francia, empezó a modificarse lentamente. Poco a poco se empezaron a celebrar las noticias venidas de los países rumanos por afinidad con el emperador austriaco, pues se entendía que, siquiera con fines puramente estratégicos, en ellos podía residir un aliado contra el Gran Turco'. No en vano, los príncipes y gobernadores o boieri se habían apresurado a firmar alianzas con los enemigos del Imperio Otomano. En este sentido, es paradigmático el caso de Şerban Cantacuzino de Valaquia que, a la vez que le estaba ofreciendo un acuerdo a Austria, se encontraba también negociando con Rusia. No fue el único que coqueteó con la posibilidad de conseguir por fin la tan ansiada independencia del Imperio turco, como lo demuestra el conato de libertad que existió en el caso de Moldavia entre 1711 y 1714, años en que el tratado firmado con el zar Pedro el Grande permitió reconocer al país moldavo como algo más que un satélite de los turcos (Hitchins 2014: 44-45).

Aun así, si nos ceñimos a lo ocurrido entre 1683 y $1687^{10}$, los años en que se

${ }^{8}$ Las relaciones ciertamente eran aún tensas en 1670 . Así parecen demostrarlo las palabras de Setton cuando recuerda que, ante el temor de una invasión de su territorio, el príncipe “[Francis I] Ráckózy, who was adrift in Hungary, had been putting pressure on Michael I Abafi [sic], the prince of Transylvania (1661-1690), to afford him a safe refuge, but Abafi [sic], a tool of the Turks, denied him access to Transylvania in order not to become embroiled with the Hapsburgs" (1991: 248).

${ }^{9} \mathrm{El}$ avance de las tropas austriacas y sus aliados propició que: "Reconquered territories would revert to their former Christian owners. As always, the other Christian princes would be urged to join the anti-Turkish league. The Russians might have been effective helpmates, but Moscow was in near chaos during the minority of Peter I and the regency of his half-sister Sophia. Also the Porte was making every effort to pacify and reassure the Russians. The German princes, however, as well as Cosimo III de' Medici, the Hospitallers, and others soon showed their willingness to support the Christian cause against the Turks by contributing (or leasing) the services of their soldiers and seamen to the multiple forces of the Holy League. Bavarian and Hanoverian troops were to be found in the Christian ranks in both Hungary and the Morea. The Turks thus had to face the Poles in Podolia, the Austrians and their allies in Hungary and Transylvania, and the Venetians in Dalmatia, continental Greece, and the Morea" (Setton 1991: 272-273).

${ }^{10}$ Aunque la guerra no terminará strictu sensu hasta la paz de Karlowitz firmada el 26 de enero de 1699, la mayor parte de los sucesos reflejados en las relaciones españolas tienen lugar mucho antes. Responden, por tanto, a lo que Setton resume del siguiente modo: "On 23 July [1687] the bulk of the Venetian army was landed near Patras, defeated the main Turkish force remaining in the Morea, and promptly occupied the city of Patras, an important acquisition. Thereafter the Christian troops seized the twin forts of 'Rumelia' and 'Morea' on the north and south shores of the entrance into the Gulf of Corinth. Next they took the castle at Lepanto, 
desarrolló la mayor parte de la guerra, la concepción que se tenía de Transilvania (o de Valaquia) no era de entrada especialmente halagüeña, dada su dependencia del Imperio otomano. Eso no quita, aun así, para que sus nombres aparezcan entre las gacetas, novas y relaciones de sucesos más difundidas por Castilla y Aragón e impresas - sobre todo- en los talleres sevillanos y madrileños. No en vano, coincide en el tiempo esta nueva manera de propaganda con la época de Carlos II (en España) y Leopoldo I (en Austria), marido de la hermana del monarca español y sobrino de Felipe IV. Los intereses políticos (como después se verá mucho más claramente durante la guerra de Sucesión española) no eran pequeños. Esa se puede considerar la razón, en parte, por la que en 1682 el regente español promulga desde Aranjuez una ley (y varias órdenes) "en que se concede la mayor importancia a cuanto guardaba relación con los asuntos de gobierno” (Simón Díaz 1983: 13). De hecho, desde 1663 se había intentado controlar la difusión de noticias a través de las gacetas y relaciones de sucesos por medio de sucesivas disposiciones y autos. En ellos se llegó a prohibir - por completo entre 1680 y 1683, y sin licencia previa a partir de entonces-y se mandó perseguir cualquier impreso de esta naturaleza que no hubiese sido autorizado (Reyes Gómez 2000: 338-350).

Aun así, pese a los escolios y a las prohibiciones, no es raro encontrar narraciones de los hechos y descripciones de las tierras afectadas - en que no se excluye el componente mítico- al hilo de los cambios políticos que estaban teniendo lugar en Centroeuropa por esos años. En ese contexto, los regentes cristianos a menudo eran considerados la encarnación del emperador universal, garante de la paz y representante de una nueva Edad de Oro, del mismo modo que se presentaba la figura de Saturno en la cuarta bucólica de Virgilio. Según el poeta latino, estaba por llegar un niño que "recibirá [...] la vida de los dioses y con los dioses contemplará a los héroes mezclados y a él mismo lo verán entre ellos y regirá el mundo apaciguado por las virtudes de su padre" (Virgilio, 1990: 188). Tales atributos habían sido adjudicados también, desde Augusto, a muchos otros dirigentes del mundo occidental, entre los que se puede destacar a Carlomagno (c. 742-814), Federico I de Hohenstaufen, Barbarroja (1122-1190) o el emperador Carlos V (De Armas, 2016: 37-39 y 50-52). Durante los años ochenta del siglo

the ancient (and modern) Naupactus. The Turks set fire to the lower town of Corinth before abandoning the seemingly impregnable fortress of Acrocorinth. They also withdrew from the historic ramparts of Castel Tornese on the northwest coast of the Morea opposite the island of Zante. Their resistance to the Venetians had crumbled everywhere in the peninsula, and they had to pull out of Mistra, capital of the old Byzantine despotate of Mistra [...] On 12 August (1687), as we have noted, Lorraine had inflicted an overwhelming defeat upon the main Turkish army under the grand vizir Suleiman Pasha near the village of Darda, just south of historic Mohács. By 21 August Morosini and von Königsmarck had crushed the Turks in the Morea. Celebrations were held in Rome, Ferrara, Padua, and elsewhere [...] The Venetians now possessed all the Morea except for Monemvasia, the rugged, island fortress on the southeast coast of the peninsula. Monemvasia remained in Turkish hands until 1690" (Setton 1991: 299-230). 
XVII, sin embargo, el dominus mundi en el que estaban depositadas todas las esperanzas del mundo católico era Leopoldo I de Austria. Según lo que se puede leer en las crónicas de la restauración de Hungría en el catolicismo, fue el "César Augustísimo Leopoldo" (Bizozeri 1687: 57), "Emperador de los Romanos" (Bizozeri 1687: 22), quien recuperó las tierras de influencia turca para el papa Inocencio XI. Lo hizo "a gritos de 'Viva la fe', [...] quitada de tirana esclavitud en que miserablemente la tenían los otomanos [...], siguiéndose como instrumentos la dirección, prudencia y valor del César Leopoldo" (Bizozeri 1687: 158). El carácter mítico del emperador resulta patente en el texto, además, si tenemos en cuenta que poco más adelante se incide en la esencia de esa nueva cruzada, ideada "para defender la Fe católica contra tantos monstruos de herejías e infidelidades" (Bizozeri 16887: 235). Igual que en el texto virgiliano, la llegada de Leopoldo I — siempre según el autor de sus hazañas recogidas en la Hungría restaurada - había sido pronosticada unos años antes. Tal y como allí se refiere:

[...] en el año de 1683, en el lugar de Lupia, reino de Nápoles, al cavar para hacer los cimientos de un monasterio de los padres de San Pedro de Alcántara, se halló, en una cara trabajada a la mosaica, un lugar en cuyo medio había un pozo o fuente, y encima una águila imperial de dos cabezas. En el muro, pues, se halló esta inscripción: Cum Dominus hoc fonte et antro potietur, Turca occidet. Quiera la divina misericordia hacer verdaderos estos presagios. (Bizozeri 1687: 235)

El origen mesiánico del emperador y las connotaciones míticas de su empresa parecen estar latentes también en los "papeles" de noticias que circularon por la Península al llegar a la guerra austro-turca de $1683^{11}$. El interés de los lectores por los sucesos relacionados con los vecinos más alejados de Europa, que se acercaban así al conflicto desde una marcada visión del mundo, no debió de ser pequeño. De este modo, al menos, parece indicarlo la publicación en Amberes y en la tardía fecha de 1688 de un libro atribuido a Gaspar Bouttats que ofrece, en castellano, una Breve y exacta descripción de los reinos de Hungría, Dalmacia y Morea juntamente [con] los principados de Transilvania, Valaquia, Bulgaria, etc. (Amberes, Juan Bautista Verdussen, 1688) (Duarte 2007: 261). La publicación viene acompañada por casi un centenar de grabados calcográficos con mapas y dibujos de las poblaciones más representativas de la zona y en ella

${ }^{11}$ Considera muy acertadamente Usunáriz, al estudiar los numerosos presagios celestes relacionados con las guerras que enfrentaron a la Casa de Austria con el Imperio otomano, que "los cuerpos celestes que aparecerían años más tarde tendrían una significación similar: la próxima caída del imperio otomano y la recuperación de la 'casa santa' de Jerusalén, gracias a la iniciativa del monarca español y del emperador. Esto se haría más evidente a partir de la década de los setenta del Seiscientos, cuando la ofensiva turca en Europa dio lugar a un enfrentamiento continuado hasta alcanzar su cénit en 1683 con ocasión del segundo sitio de Viena” (2016: 67). 
se encuentra una detallada descripción (geográfica e histórica) de los principados de Transilvania y Valaquia, entre otros. Su intención, como parece obvio, tiene mucho que ver con la tensión existente entre esos poderes políticos orientales y occidentales que venimos estudiando aquí, otorgando con su redacción de la guerra una pátina mítica y aun sagrada de los avances llevados a cabo por las tropas austriacas. De este modo, tanto en el grabado calcográfico que abre el volumen, en el que podemos ver una representación alegórica de "la Santa Iglesia triunfando sobre los incrédolos", como en la nota "Al curioso lector" no puede quedar más claro el objetivo del impreso:

Cómo la guerra presente que tienen entre el sultán turco Mahomet (el cuarto deste nombre), el poderosísimo emperador Leopoldo el primero, el valeroso rey de Polonia y la serenísima república de Venecia, es la materia principal de la cual se discurre. En algunas horas ociosas, en la mayor parte de las compañías, hemos hallado de por bueno que no sería de poco servicio, y no de poco gusto para los curiosos, que se les diera con esta ocasión una circunstante descripción, tan breve y compendiosa que ha sido posible, de los reinos, principados, provincias y villas, unas cerca de otras situadas, a lo natural en estampa retratadas, donde las hodiernas armas, como en un teatro de guerra, lo más están retratadas. Y para introducción dellas, hemos antepuesto una mapa geográfica de mar y tierra para señalar dónde, cómo y en cuál parte todas las provincias, villas y plazas están situadas, donde las gloriosas armas de los sobrenombrados invincibles generales sus victorias embisten. (Bouttats 1688: 3)

Al entrar de lleno en sus páginas se ve también claramente la imagen de los países rumanos que se quería transmitir por esas fechas al público de la Península Ibérica. Transilvania, la primera en aparecer, es la que se ve tratada con mayor amabilidad, probablemente por la ayuda prestada a las tropas austriacas. Se encuentra descrita, incidiendo primeramente en sus raíces clásicas, como "la parte media de Dacia la antigua" (Bouttats 1688: 27). Pero no solo eso pues, además, en la medida en que lo consideremos un territorio afín a la expansión del emperador Leopoldo I, no debería extrañarnos que se describa como una tierra fértil y de "muy hermosos y gustosos vinos" (Bouttats 1688: 28). A fin de cuentas, si aceptamos que algunos de los autores de estos relatos bélicos tienden a ver al futuro rey de Hungría como ese "caro vástago de los dioses, gran descendencia de Júpiter" que anunciaba Virgilio (1990: 189-190), es lógico que a su paso se vaya instaurando una nueva Edad de Oro similar a la que Hesíodo dejó descrita en los Trabajos y días o a la que don Quijote rememoraba entre cabreros. Sea como fuere, la subsiguiente descripción de sus gentes, desde la Antigüedad hasta el momento de la guerra que se recoge en la Descripción de 1688 , se limita a pasar nómina a las distintas poblaciones que han habitado en sus tierras, aunque no lo hace sin incidir en que: "este principado mudó muchas 
veces del servicio de Dios por muchos herejes, los cuales introdujeron su falsa doctrina debajo de diferentes príncipes" (Bouttats 1688: 29). Con todo, la lista de príncipes transilvanos termina con "Miguel Abafi [i.e. Mihály Apafi], [quien] por intervención de los turcos fue realzado por príncipe y es el que al presente domina, y el principio del año mil seiscientos ochenta y seis se hizo tributario de la cesárea majestad" (Bouttats 1688: 29).

Por su parte, Valaquia y - sobre todo- sus gentes son presentados de manera opuesta a los transilvanos, que ya se habían reconvertido - al menos en la concepción del escritor - al cristianismo. Los valacos serán "duros y ásperos de condición, poco amigos de sciencias, son perezosos y tardivos en cultivar sus tierras, puercos y sucios en sus casas" (Bouttats 1688: 32). No en vano, se apresuran los autores a dejar constancia de que "esta provincia depende del Grande Sultán o emperador turco" (Bouttats 1688: 32). Si antes destacábamos las raíces míticas que se entreveran en las relaciones de sucesos que aluden a las guerras que tuvieron lugar en la Península Ibérica en torno a 1640, las noticias impresas en las dos últimas décadas del siglo no constituyen una excepción a un tipo de discurso fantasioso - por mucho que quiera pasar por histórico- dedicado a las exóticas tierras de Transilvania o la "áspera" Valaquia. La población de este último principado, de hecho, tiene mucho que ver con "el mito del salvaje", según lo ha estudiado Roger Bartra. El antropólogo ha puesto de manifiesto que el hombre salvaje europeo es:

[...] un estereotipo que arraigó en la literatura y el arte europeo desde el siglo XII, y que cristalizó en un tema preciso fácilmente reconocible. [...] si examinamos con cuidado el tema, descubrimos un hilo mítico que atraviesa milenios y que se entreteje con los grandes problemas de la cultura occidental. Lo verdaderamente fascinante del mito del hombre salvaje es que se extiende durante un larguísimo periodo de la historia, desde su antiquísima encarnación en el Enkidu babilónico hasta nuestros días. [...] los hombres salvajes son una invención europea que obedece esencialmente a la naturaleza interna de la cultura occidental. Dicho en forma abrupta: el salvaje es un hombre europeo, y la noción de salvajismo fue aplicada a pueblos no europeos como una transposición de un mito perfectamente estructurado cuya naturaleza solo se puede entender como parte de la evolución de la cultura occidental. E1 mito del hombre salvaje es un ingrediente original y fundamental de la cultura europea. (Bartra 1992: 8-13)

De esta manera aparece, no solo en los relatos de Valaquia, sino también en las descripciones de Moldavia, retratada como un principado "singularmente fructífero en trigo, chicharos, habas, miel y cera” (Bouttats 1688: 33). Se asemeja así a Transilvania, aunque sus habitantes "son más inclinados a la guerra que a cultivar la campaña en el servicio de Dios, siguen la Iglesia griega y son dependientes del patriarca de Constantinopla, aunque aquí se hallan otras 
diferentes religiones" (Bouttats 1688: 33). No cabe duda de que este tipo de relatos históricos participan sin remilgos de la misma opinión que los gobernantes occidentales, ayudando a presentar con sus descripciones - signos literarios, a fin de cuentas - un retrato estereotipado de "los otros", habitantes de países distantes y remotos del extremo de Europa.

Como veremos a continuación, esa imagen no fue fruto de un día. Entre el aluvión de noticias que narraban los sucesos más destacados de la guerra se fue colando la situación de la actual Rumanía gracias a los tatarabuelos más lejanos de nuestros periódicos. No en vano, con ellos se consiguió aprovechar "la pervivencia en el tiempo de acontecimientos muy importantes (por ejemplo, los bélicos) para fidelizar la audiencia mediante su publicación bajo un título constante, numeración corrida y plazos periódicos fijos" (Díaz Noci 2008: 131). Así ocurrió, desde luego, con las numerosas "relaciones históricas" que vieron la luz en los años ochenta del siglo, como ya hemos comentado en estas páginas ${ }^{12}$. Baste destacar ahora que en ellas se encuentra escrita entre líneas una interesantísima historia de las regiones transilvanas y transalpinas a propósito del peligro turco y berberisco. Los papeles vendidos en los reinos de España, de hecho, culminarán con la sugerente relación extraordinaria en las que se trata de la "reunión absoluta de toda la Transilvania a la obediencia de los señores emperador y rey de Hungría y a su corona" (Relación extraordinaria 1688: [ ] 1r) ${ }^{13}$, fácilmente reinterpretable desde una perspectiva mítica y religiosa.

Con todo, merece la pena echar a andar este camino desde más atrás, con una de las más interesantes noticias llegadas a este lado del Mediterráneo, en que se recupera el pasado glorioso de la actual Rumanía para dejar constancia en 1683 del "Levantamiento de las provincias de Valaquia y Albania contra el Turco, a devoción de la Liga Cristiana" (Levantamiento de las provincias... 1683: [ ] 1r) ${ }^{14}$. El relato, como no podía ser de otra forma, se difundió rápidamente por toda la Península desde la misma Imprenta Real que se había dado a la publicación de otras "Gacetas" madrileñas para exaltar la heroicidad que se desprende de la rebelión rumana. De este modo dice la relación:

La provincia poderosísima de Valaquia, fatigada del gobierno y exacciones tiránicas del Turco, de quien en feudo pendía, viendo la ocasión oportuna

\footnotetext{
${ }^{12}$ No entramos, aun así, en este trabajo a distinguir los distintos tipos de relaciones y gacetas, tal y como hacen Díaz Noci 2008 y Rault 2008 a propósito del mismo tema.

${ }^{13}$ Relación impresa en Sevilla por Tomás López de Haro conservada en la Universidad de Sevilla, signatura A 112/044(24). Reeditada en Madrid por Sebastián de Armendáriz y Antonio Román, probablemente en el mismo año. Existe ejemplar de esa edición en la Biblioteca Nacional de España, signatura U/10326(38).

${ }^{14}$ Relación impresa en Zaragoza, s. n., 1683 (con ejemplar en la Universitat de Barcelona, signatura B-54-3-18-21) y reeditada menos de un año más tarde en Madrid por la Imprenta Real (Mateo de Llanos), a costa de Andrés Blanco.
} 
y logrando las buenas inteligencias que mantenía su majestad polaca, ha tomado las armas y echado al príncipe o hospadar que, en nombre del Imperio Otomano, la gobernaba, estableciendo en su lugar al otro príncipe que antes la había tenido en feudo [...]. (Levantamiento de las provincias... 1683: [ ]1r)

No tardará, en consecuencia, el cronista en destacar que "este nuevo príncipe de Valaquia queda feudatario al Imperio Cristiano y con guarniciones imperiales y polacas en las mejores plazas, a más de sustentar gran parte de las tropas cristianas en cuarteles de invierno" (Levantamiento de las provincias... 1683: [ ]1r).

Con todo, también es de interés para la difusión de noticias rumanas la existencia de otras relaciones como la que vio la luz en enero de 1684 en Sevilla de la mano de Cristóbal López. En ella "confírmase asimismo la rebelión contra el Turco de las provincias de Albania, Valaquia y Moldavia y se avisa de la Liga que ha hecho la república de Venecia con los señores emperador y rey de Polonia, a instancia de su Santidad, para la defensa de la Iglesia" (Relación verdadera 1684: A1r $)^{15}$. Este último, de hecho, se presenta en las relaciones como uno de los actores determinantes en el devenir de la guerra en favor del imperio de Leopoldo I, que terminará por convertirse también en rey de Hungría (y parte de Transilvania) en 1690. Tal es su relevancia en los papeles noticiosos que se llega a decir que "el señor rey de Polonia" fue fundamental en la victoria que tuvo lugar en Viena en diciembre de 1684, aunque "si bien añadiendo que su majestad imperial, como amigo, le hubiera pedido asistencias, le hubiera socorrido a medida de las grandes fuerzas con que se halla" (Relación verdadera 1684: A4v).

La presencia de los principados rumanos actuando como telón de fondo de la guerra se corrobora, asimismo, en varias de las relaciones impresas en 1686, uno de los años más fértiles en lo que a la difusión de noticias respecta. En ellas queda claro que el rey polaco no es el único aliado de la Santa Liga. Es cierto que el 7 de mayo de ese año, en particular, se destacan los "recelos del proceder del príncipe transilvano" (Relación bistórica 1686a: $55 \mathrm{r}$ ) ${ }^{16}$, de quien se sospecha "que se entiende con los infieles" (Relación histórica 1686a: 56v). También por entonces se hace constar la oposición de los valacos y moldavos a las tropas polacas que lucharon del lado de "las armas cesáreas" (Relación histórica 1686a: 56r). Sin embargo, la imagen de estos pueblos no parece resentirse, probablemente porque:

[...] el coronel Orchitz, con un cuerpo de mil hombres, se apoderó de la villa de Yuderovia por asalto y después de saqueada la pegó fuego, habiendo perecido gran número de turcos en la mesma ocasión, y lo que particularmente

${ }^{15}$ Con ejemplar en la Universidad de Sevilla, signatura A 112/111(61).

${ }^{16}$ Relación impresa en Madrid por Antonio Román. Existe ejemplar en la Universitat de Barcelona, signatura C-240-6-8-107. 
El mito de Transilvania en la España de Carlos II: imagen, identidad y conflicto en las noticias impresas durante la guerra austro-turca

señaló su acción fue traer consigo de vuelta ducientos valacos, que se pasaron al servicio de Su Mag. Imperial. (Relación histórica 1686a: 57r-57v)

La dilación por parte de los transilvanos enviados a mediar frente al emperador austriaco, en fin, no tardó en resolverse. En la misma línea que en las anteriores, presentando las tropas del emperador austriaco como libertadoras de la opresión del enemigo, se pueden leer las líneas que se le dedican a los sucesos acaecidos en el mes siguiente. En la relación publicada el 18 de junio se dice que ha entrado también Rusia en la contienda contra el Imperio otomano:

[...] quedando empero fijo que los moscovitas invadirían con un poderosísimo ejército la Crimea, obligando a los tártaros a cuidar de la defensa de aquella su patria en lugar de guerrear por los turcos, que en esta diversión (puédese decir sin encarecimiento) perderán su brazo derecho y el mejor nervio de sus fuerzas. En esta idea se fundan especialmente las esperanzas de que los príncipes de Moldavia y Valaquia, libres de las vejaciones de aquellos bárbaros, entren también en la confederación. (Relación histórica 1686b: 73v) ${ }^{17}$

Algo más tarde, en las noticias impresas el 2 de julio de ese mismo año (que se continúan en las del día 9 de julio) cambia completamente el tono con que se acogen las nuevas sobre el príncipe Apafi. Se alaba allí la feliz noticia de que "grandes indicios (si ya no evidencias) hay del proceder sincero del príncipe de Transilvania, en orden a observar su tratado y obrar a favor de la Liga Sagrada” (Relación bistórica 1686c: 78r-78v) ${ }^{18}$. Su alineamiento junto a las filas austriacas se llega a convertir en ejemplo para las tierras de Valaquia y Moldavia, a las que se insta el día 9 de julio a "seguir brevemente su ejemplo, pues de no hacerlo se expondrían a caer en el mesmo precipicio de que parecía imposible se pudiesen eximir los otomanos, no habiendo tenido jamás la Cristiandad tantas fuerzas ni tan bien gobernadas como este año contra ellos" (Relación histórica 1686d: 92v) ${ }^{19}$. La incorporación también de las tierras transalpinas a la ofensiva contra el Gran Turco se da ya, desde luego, como un hecho consumado en agosto de ese mismo año (Relación histórica 1686e: $115 \mathrm{r})^{20}$.

Al fin, con la toma de la mayor parte de las plazas otomanas en el verano de 1687, empiezan a aparecer también nuevas noticias de la "ratificación de los

${ }^{17}$ Edición impresa en Madrid por Sebastián de Armendáriz y Antonio Román en 1686. Existe ejemplar en la Universitat de Barcelona, signatura C-240-6-8-65.

${ }^{18}$ Relación impresa en Madrid por Sebastián de Armendáriz y Antonio Román. Existe ejemplar en la Universitat de Barcelona, signatura C-240-6-8-103.

${ }^{19}$ Relación impresa en Madrid por Sebastián de Armendáriz y -aunque sin firmar-Antonio Román. Existe ejemplar en la Universitat de Barcelona, signatura C-240-6-8-101.

${ }^{20}$ Relación impresa en Madrid por Sebastián de Armendáriz y Antonio Román. Existe ejemplar en la Universitat de Barcelona, signatura C-240-6-8-99. 
tratados con Transilvania" (Relación histórica 1687a: 35r) ${ }^{21}$ y, sobre todo, de la "restauración entera de las dos provincias de Esclavonia y Rascia, la Transilvania obediente al César, Atenas tomada de Venecianos, y primeras noticias de la Entrega de Negroponte a las mesmas Armas Venecianas" (Relación bistórica 1687b: 149r) 22. La relación del 9 de diciembre de ese año resulta, por tanto, para nuestro propósito una de las más interesantes, pues en ella se incluye una "Breve descripción de la Transilvania” ${ }^{23}$ muy parecida a la que se podrá leer un año más tarde también en la Breve y exacta descripción de los reinos de Hungría, Dalmacia y Morea, ya comentada en estas páginas. En esta ocasión la región aparece nuevamente retratada como un vergel recién salido de la Edad de Oro antes que como el escenario de la guerra austro-turca. Se dice de ella que es una zona "fertilísima de todo género de granos y legumbres. Todas sus muchas colinas, blandas y amenas, están cubiertas de viñas, que producen vinos poco diferentes en la generosidad y gusto de los de Hungría, que en algo pueden compararse con los de Andalucía" (Relación extraordinaria 1687: A1v).

Por su parte, sus habitantes, divididos en sículos, húngaros y sajones — según la relación-, "profesan la religión y ritos griegos, salvo los que han admitido las herejías modernas, hallándose casi todo el principado inficionado de los errores de Lutero y Calvino, y aun de los de Arrio, resucitados de cerca un siglo a esta parte" (Relación extraordinaria 1687: 2r). El texto, en fin, termina dando cuenta de la ayuda del príncipe Apafi, aunque reprochándole que "si en esta ocasión hubiera fiado menos de sus acostumbrados dobleces y procedido con más llaneza, parece que hubiera ido mejor" (Relación extraordinaria 1687: 3r).

Pese a todo, el final del conflicto no deterioró las relaciones hispano-rumanas tanto como cabría esperar. En una hoja volandera impresa en 1688 por Pedro de Cleyn se pueden leer los Artículos del tratado concluido por el serenísimo Duque de Lorena con el principe Miguel Abafi [sic.] y estados de Transilvania ${ }^{24}$. El trato, desde luego, parece conforme a los acuerdos adquiridos, pues Transilvania se compromete a alojar los regimientos imperiales austriacos mientras que los estados de la Hermandad prometen — principalmente- "que no se hará molestia alguna directa ni indirecta a las cuatro diferentes religiones que al presente se profesan en Transilvania", "que no se dará crédito a falsos testimonios y acusaciones que se pudieren levantar contra el príncipe y estados de haber hablado mal de su Majestad Imperial o de sus generales" y "que no se tocará en los bienes de los transilvanos, dejándolos gozar pacíficamente” (Artículos 1688: A1r-A1v).

${ }^{21}$ Relación impresa en Madrid por Sebastián de Armendáriz y Antonio Román. Existe ejemplar en la Universidade de Coimbra, signatura VOL CDLXXXVI 8223.

${ }^{22}$ Universidade de Coimbra, signatura VOL CDLXXXVI 8235.

${ }^{23}$ Relación impresa en Madrid por Sebastián de Armendáriz y Antonio Román. Existe ejemplar en la Universidad de Sevilla, signatura A 109/028(28).

${ }^{24}$ Existe ejemplar de este pliego en la Universidad de Sevilla, signatura A 112/044 (20). 
Todas esas noticias son las que ayudan a construir el último de los testimonios que comentaremos en este trabajo. Se trata de la detallada exposición que se hace de la guerra en la Hungría restaurada, compendiosa noticia de dos tiempos; del pasado, bajo el yugo de la tiranía otomana, y del presente bajo el dominio católico de Leopoldo II [sic.] de Austria. Felices sucesos de sus armas cesáreas en el reino de Croacia y principado de Transilvania, ya citado a lo largo de estas páginas. Se trata, en realidad, de una traducción — según la información de la portadade la obra que escribió en toscano Simpliciano Bizozeri. No obstante, aunque redactada por mano extranjera, el texto se ajustaba muy bien a los intereses de los castellanos y aragoneses, razón por la que apareció impresa en Barcelona en un volumen que el autor utilizó para "ofrecerte estos que intitulo laureles cesáreos en la restauración de Hungría” (Bizozeri 1688: [ ] 2v). En él, tras historiarse los orígenes de las regiones húngara y austriaca, se pasa a tratar con detalle de las décadas de luchas que habían discurrido en oposición al Gran Turco hasta llegar a "los efectos que se siguieron en el año de 1683" (Bizozeri 1688: 36). Lo que más nos interesa en esta ocasión, sin embargo, es el apartado que aparece tras la descripción de los condados húngaros, dedicado a los principados rumanos en función de su participación en la guerra. Como viene siendo habitual, en la "Breve noticia de Transilvania" que se encuentra al final del volumen se incide en sus riquezas materiales, pero también se exponen otros aspectos más descuidados en los documentos anteriores, como su situación política (presentada con especial atención a su régimen interno), su religión (o sus religiones), su población (dividida en alemanes, sajones, húngaros, sículos, moldavos y valacos) y sus principales ciudades. La atención prestada a su historia, por fin, culmina con un breve párrafo dedicado a Mihály Apafi (o Miguel Abafi), el príncipe responsable de mediar en la guerra austro-turca. La imagen que sobre él se vierte parece coincidir con la mesura con que se trata también a los transilvanos en el tratado firmado con el Duque de Lorena, pues se dice de él que:

aún hoy día rige aquel principado, y creo con mucha prudencia, particularmente en las presentes coyunturas de guerra, manifestándose menos inclinado a los Turcos, los cuales desearan verle empleado con todas sus fuerzas dese principado en daño de la Casa de Austria. (Bizozeri 1688: 269)

Como se puede comprobar por lo expuesto hasta aquí, los países rumanos no fueron unos desconocidos para los lectores de noticias del Siglo de Oro. Su realidad, mediada por las guerras y los intereses políticos que marcaron Europa durante la Edad Moderna, estuvo presente en buena parte del Seiscientos y el interés que despertaban sus lejanas tierras se dejó notar especialmente en la década de los ochenta como el telón de fondo sobre el que se dibujaba mucho más vivamente la guerra austro-turca. Su realidad se describió en diversos momentos, como hemos desarrollado en las páginas anteriores, y algunos impresores 
supieron sacarle un rendimiento nada desdeñable. Desde Sevilla, impresores acostumbrados a vender hojas volanderas dentro de un proyecto editorial mucho más amplio y provechoso, como Tomás López de Haro, no dudaron en componer en letras de molde algunos de los más notables sucesos acaecidos en el este de Europa (Pérez González 2013). De igual manera, a juzgar por la insistencia en el tema de los madrileños Antonio Román y Sebastián de Armendáriz, tampoco a ellos debió de irles mal con la impresión de las hazañas bélicas del Imperio austriaco. Desde luego, si tenemos en cuenta que su actividad parece limitarse precisamente a los años que duró la guerra, no puede quedar ninguna duda de la rentabilidad del tema; sobre todo si consideramos que también ellos son los responsables de imprimir la comedia de La restauración de Buda de Bances Candamo en 1686, donde se retratan precisamente los mismos hechos (Duarte 2007). Llama la atención, sin embargo, que los relatos más extensos de la guerra decidan salir fuera de Castilla (a Amberes o a Barcelona) para presentarse ante los mismos lectores que debieron de coleccionar las relaciones impresas por la pareja antedicha.

En cualquier caso, los elementos en los que se suele poner el foco son casi siempre los mismos. La imagen mítica del emperador Leopoldo I de Austria, retratado con cierto carácter mesiánico, se da la mano con una descripción marcadamente literaria de la realidad transilvana o valaca. En los impresos se alude a menudo a la amistad (en el caso de Transilvania) o la enemistad (en los casos de Valaquia y Moldavia) existente con el Imperio austriaco y, por extensión, con toda la Santa Liga y los reinos peninsulares. Eso incide, además, directamente en la manera de presentar tanto la tierra (con hincapié en su fertilidad, convirtiéndose casi en el idílico entorno de la Edad de Oro descrita por Hesíodo) como a sus habitantes, caracterizados como herejes y practicantes de las más diversas religiones en los casos en que existe un enfrentamiento directo. El conflicto bélico que mueve a toda Europa es también, en el contexto de los documentos analizados en este trabajo, un conflicto religioso y, en última instancia, un conflicto político-económico.

Con este trabajo simplemente hemos presentado un tema que merece ser abordado con muchísima más profundidad. Las pequeñas calas que hemos hecho en estas páginas dan cuenta de la riqueza que existe en la imagen (a caballo entre lo mítico y lo real) de los principados rumanos, trasmitida en esta ocasión de manera específica para un público lector hispanohablante. Sirva, en fin, este artículo para dejar constancia de la presencia - intermitente- de los países rumanos en las prensas castellanas y aragonesas a lo largo de toda la Edad Moderna e iniciar con ello un debate sobre la visión del espacio rumano que existió en España. 
El mito de Transilvania en la España de Carlos II: imagen, identidad y conflicto en las noticias impresas durante la guerra austro-turca

\section{Bibliografía}

Arredondo, Ma Soledad (2011), Literatura y propaganda en tiempo de Quevedo: guerras y plumas contra Francia, Cataluña y Portugal. Madrid / Frankfurt: Iberoamericana / Vervuert.

Articulos del tratado concluido por el serenisimo Duque de Lorena con el príncipe Miguel Abafi [sic.] y estados de Transilvania (1688). [Bruselas]. Pedro de Cleyn.

Bartra, Roger (1992), El salvaje en el espejo. México D. F.: Universidad Nacional Autónoma de México / Ediciones Era.

Bizozeri, Simpliciano (1687), Hungría restaurada, compendiosa noticia de dos tiempos. Barcelona: Antonio Ferrer, Baltasar Ferrer y Joan Cassañas / Martín Gelabert.

Boadas Cabarroca, Sònia (2012). Un diálogo hacia la paz: las "Locuras de Europa" de Diego de Saavedra Fajardo, tesis doctoral dirigida por el Dr. Jorge García López. Girona: Universitat de Girona. [http://hdl.handle. net $/ 10803 / 83619]$.

Bouttats, Gaspar (1688). Breve y exacta descripción de los reinos de Hungría, Dalmacia y Morea. Amberes: Juan Bautista Verdussen / Gaspar Bouttats.

Brown, Jonathan y Elliott, John H. (2003), Un palacio para el rey. Madrid: Taurus.

Burke, Peter (2000), Formas de Historia Cultural. Madrid: Alianza.

De Armas, Frederick A. (2016), El retorno de Astrea: astrología, mito e imperio en Calderón. Pamplona / Madrid / Frankfurt: Universidad de Navarra / Iberoamericana / Vervuert.

Díaz Noci, Javier, "El Mediterráneo en guerra: relaciones y gacetas españolas sobre la guerra contra los turcos en la década de 1680", en Pierre Civil, Françoise Crémoux y Jacobo Sanz (eds.), España y el mundo a través de las relaciones de sucesos (1500-1750). Salamanca: Universidad de Salamanca, 131-140.

Domènech, Conxita (2016), La 'Guerra dels Segadors' en comedias y panfletos ibéricos: una bistoria contada a dos voces (1640-1652). Kassel: Reichenberger.

Duarte, J. Enrique, "Fuentes y representación de La restauración de Buda", en Felipe B. Pedraza Jiménez, Rafael González Cañal, Elena Marcello (eds.), Guerra y paz en la comedia española: XXIX Jornadas de Teatro Cásico de Almagro. Almagro: Universidad de Castilla-La Mancha, 259-274.

Ettinghausen, Henry (1993), La Guerra dels Segadors a través de la premsa de l'època, 4 vol. Barcelona: Curial.

García Castañón, Santiago (2011), "El teatro como propaganda al servicio de la corona durante el reinado de Carlos II: el caso de La restauración de 
Buda, de Bances Candamo", en Compostella Aurea. Actas del VIII Congreso de la AISO. Santiago de Compostela: Universidade de Santiago de Compostela, vol. III, 171-179.

García Reidy, Alejandro (2013), Las musas rameras: oficio dramático y conciencia profesional en Lope de Vega. Madrid / Frankfurt am Main: Iberoamericana / Vervuert.

Gernet, Louis (1981), "Value in Greek Myth", en R. L. Gordon (ed.), Myth, Religion and Society. Cambridge: Cambridge University Press, 111-146.

González Cañal, Rafael (1987), “Tres escritos desconocidos de D. Diego Saavedra Fajardo", Revista Murgetana, núm. 73: 51-90.

Gutiérrez, Carlos M. (2005), La espada, el rayo y la pluma: Quevedo y los campos literario y de poder. West Lafayette: Purdue University Press.

Hitchins, Keith (2014), A concise History of Romania. New York: Cambridge University Press.

Levantamiento de las provincias de Valachia y Albania contra el Turco a devoción de la Liga Cristiana (1683). Zaragoza. S. n.

López Poza, Sagrario (2009), “Estereotipos del 'otro’ en representaciones icónicas descritas en relaciones festivas", en Patrick Begrand (ed.), Representaciones de la alteridad, ideológica, religiosa, humana y espacial en las relaciones de sucesos, publicadas en España, Italia y Francia en los siglos XVI-XVIII. Paris: Presses Universitaires de Franche-Comté, 425-442.

Pellicer y Tovar, José de (2006), Defensa de España contra las calumnias de Francia (1635), Antonio López Ruiz y Antonio José López Cruces (eds.). Alicante: Biblioteca Virtual Miguel de Cervantes. [http://www.cervantesvirtual. com/nd/ark:/59851/bmcdf744].

Pérez González, Andrea Mariel (2013), Literatura española en la Nueva España: Cinco catálogos sevillanos de la década de 1680, Trabajo de Fin de Máster dirigido por el Dr. Víctor Infantes de Miguel. Madrid: Universidad Complutense de Madrid. [http://eprints.sim.ucm.es/23788/].

Rault, Didier, "La lucha naval con turcos y berberiscos en el Mediterráneo según las relaciones de sucesos (siglo XVII)", en Pierre Civil, Françoise Crémoux y Jacobo Sanz (eds.), España y el mundo a través de las relaciones de sucesos (1500-1750). Salamanca: Universidad de Salamanca, 237-252.

Redondo, Agustin, "E1 mundo turco a través de las relaciones de sucesos de finales del s. XVI y de las primeras décadas del s. XVII: la percepción de la alteridad y su puesta en obra narrativa”, en Antonia Paba (ed.), Encuentros de civilizaciones (1500-1750). Informar, narrar, celebrar. Madrid: Universidad de Alcalá de Henares, 235-253.

Relación de todo el cerco de Temesuar, hasta que el Principe de Transilvania alzó el campo ([1596]). Sevilla. Rodrigo Cabrera. 
El mito de Transilvania en la España de Carlos II: imagen, identidad y conflicto en las noticias impresas durante la guerra austro-turca

Relación extraordinaria de lo ocurrido últimamente en la reducción y reunión absoluta de toda la Transilvania a la obediencia de los señores emperador y rey de Hungria y a su corona (1688). Sevilla. Tomás López de Haro.

Relación extraordinaria de los progresos de las armas cristianas contra turcos en la Hungria y Grecia [...] Publicada el martes 9 de diciembre (1687). [Madrid]. Sebastián de Armendáriz / Antonio Román.

Relación histórica del año 1686 [...] Publicada el martes 7 de mayo (1686a). [Madrid]. Sebastián de Armendáriz / Antonio Román.

Relación histórica del año 1686 [...] Publicada el martes 18 de junio (1686b). [Madrid]. Sebastián de Armendáriz / Antonio Román.

Relación histórica del año 1686 [...] Publicada el martes 2 de julio (1686c). [Madrid]. Sebastián de Armendáriz / Antonio Román.

Relación histórica del año 1686 [...] Publicada el martes 9 de julio (1686d). [Madrid]. Sebastián de Armendáriz / Antonio Román.

Relación histórica del año 1686 [...] Publicada el martes 13 de agosto (1686e). [Madrid]. Sebastián de Armendáriz / Antonio Román.

Relación histórica del año 1687 [...] Publicada el martes 25 de marzo (1687a). [Madrid]. Sebastián de Armendáriz / Antonio Román.

Relación histórica del año 1687 [...] Publicada el martes 2 de diciembre (1687b). [Madrid]. Sebastián de Armendáriz / Antonio Román.

Relación verdadera y noticias generales venidas con el correo de Flandes en $1^{\circ}$ de enero de 1684 (1684). Sevilla. Cristóbal López.

Reyes Gómez, Fermín de los (2000), El libro en España y América: legislación y censura (siglos $X V$-XVIII), 2 vols. Madrid: Arco Libros.

Sáez, Adrián J. (2011), Hacia una bibliografía sobre autoridad y poder en el Siglo de Oro. Pamplona: Publicaciones digitales del GRISO. [http://www.unav. edu/centro/griso/otras-publicaciones-digitales].

Sâmbrian, Oana Andreia, (2013), “'Preocupations for space, travel and travellers in Romania': an interview with Ovidiu Cristea, director of the 'Nicolae Iorga' History Institute from Bucharest”, Hispania Felix, núm. 4: 22-26. (2015), Imaginea Tansilvaniei în Spania în timpul Războiului de Triezeci de Ani (1618-1648). Craiova: Editura Sitech.

Setton, Kenneth Meyer (1991), Venice, Austria and the Turks in the Seventeenth Century. Independence Square (Philadelphia): The American Philosophical Society.

Simón Díaz, José (1983), El libro español antiguo: análisis de su estructura. Kassel: Reichenberger.

Usunáriz, Jesús M. (2016), España en Alemania: la Guerra de los Treinta Años en crónicas y relaciones de sucesos, New York: IDEA/IGAS. 
Valladares, Rafael (2002). Teatro en la guerra: imágenes de principes y Restauración en Portugal. Badajoz: Departamento de Publicaciones de la Diputación de Badajoz.

Verjat, Alain (2000), "Mitemas del héroe", Théleme. Revista Complutense de Estudios Franceses, núm. 15: 153-164.

Virgilio Marón, Publio (1990), Bucólicas. Geórgicas. Apéndice virgiliano, Tomás de la Ascensión Recio García y Arturo Soler Ruiz (trad.). Madrid: Gredos. 